\title{
HETERO $\mathrm{CuO}_{x} / \mathrm{ZnO}$ MICRO-/NANOSTRUCTURE: CARBOTHERMAL REDUCTION-VAPOUR PHASE TRANSPORT
}

\author{
A. Rahmati ${ }^{\text {a, b }}$, F. Rahimi Bayaz ${ }^{\text {a, b }}$, A. Lotfiani ${ }^{\text {c }}$, and M. Kouhestani ${ }^{\text {d }}$ \\ a Department of Physics, Faculty of Science, Vali-e-Asr University of Rafsanjan, 7718897111 Rafsanjan, Iran \\ ${ }^{\mathrm{b}}$ Nanostructure Laboratory, Department of Physics, Faculty of Science, Vali-e-Asr University of Rafsanjan, \\ 7718897111 Rafsanjan, Iran \\ ' Laser and Plasma Research Institute, Shahid Beheshti University, P.O. Box 198396-3113, Evin, Tehran, Iran \\ ${ }^{d}$ Physics Department, Payame Noor University, P.O. Box 19395-3697, Tehran, Iran \\ Email: alirahmati1980@gmail.com
}

Received 10 April 2017; revised 19 May 2017; accepted 15 June 2017

\begin{abstract}
$\mathrm{ZnO}$ micro-/nanostructures were synthesized by the carbothermal reduction-chemical vapour transport method. This work is focused on the effect of the substrate temperature and $\mathrm{Cu}$ catalyst layer on the shape and geometry of $\mathrm{ZnO}$ micro-/nanostructures. The thermally oxidized $\mathrm{Cu}$ template affects the structure, chemical identity, optical and photoluminescence properties of the $\mathrm{ZnO}$ micro-/nanostructure and results in a $\mathrm{CuO}_{x} / \mathrm{ZnO}$ heterostructure. SEM studies give a direct evidence of the role of deposition temperature and $\mathrm{Cu}$ catalyst in the formation of a stable hemisphere based wire, a comb-like cantilever, a javelin-like tetrapod, a spherical and polyhedral cage of ZnO. XRD and Raman measurements confirm a hexagonal wurtzite structure of the $\mathrm{ZnO}$ micro-/nanostructure. The absorption edge of the $\mathrm{ZnO} / \mathrm{CuO}_{x}$ heterostructure is redshifted in comparison to the pure $\mathrm{ZnO}$ structure. PL studies indicate that the UV emission can be suppressed significantly while the green emission is enhanced due to the change in the morphology of $\mathrm{ZnO}$ micro-/nanostructures.
\end{abstract}

Keywords: vapour phase transport growth, $\mathrm{CuO}_{x} / \mathrm{ZnO}$ heterostructure, carbothermal reduction

PACS: 68.35.-p, 73.40.Kp, 81.16.-c

\section{Introduction}

$\mathrm{ZnO}$ micro-/nanostructures have attracted a great interest owing to their excellent properties and their potential applications as nanoscale electronic, photonic, field emission, sensing, energy conversion and piezoelectric devices [1-7]. Several strategies have been developed to synthesize $\mathrm{ZnO}$ micro-/nanostructures such as vapour-phase transport [8], metalorganic vapour-phase epitaxy [9], pulsed laser deposition [10], various wetchemistry methods [5, 11], and magnetron sputtering [4], 12].

Various geometrical morphologies of $\mathrm{ZnO}$ micro-/nanostructures have been fabricated, such as rods [4, 5, 13], wires [8, 14, 15], tubes [16], combs [8], tetrapods [17], etc. However, the morphology and size control of $\mathrm{ZnO}$ micro-/nanostructures is still an issue and many groups have focused on this problem. Huang et al. [14] have suggested that the diameter of nanowires can be controlled by varying Au layer thickness and longer reaction times. Yao et al. [18] reported that the diameter of $\mathrm{ZnO}$ nanowires was temperature dependent and substrates placed in a lowtemperature zone resulted in small diameters of $\mathrm{ZnO}$ nanowires. Wang et al. [19] suggested that the formation of nanotips and nanofinger arrays on two sides of a comb ribbon was a direct result of the surface polarity of $\mathrm{ZnO}$. The polarity of the $\mathrm{ZnO}$ (0001) surface is the key enabling factor to determine micro-/nanostructures grown 
on the surface. The self-catalysed process is likely a mechanism for the growth of oxide nanostructures without the presence of foreign metallic catalysts [19].

In the present study, the systematic size and shape control of different $\mathrm{ZnO}$ nanostructures (rods, wires, cages and combs) is demonstrated by carefully controlling the growth temperature, template and initial precursor. Morphology, dimensional control, structural, chemical bonding and optical characterizations, and discussion on the related growth mechanism are presented.

\section{Experiment and methods}

A horizontal one-side opened quartz tube (inner diameter $50 \mathrm{~mm}$, length $100 \mathrm{~cm}$ ) was placed inside a high-temperature tube furnace as shown in Fig. 1(a). The Cu template was deposited on a series of the cleaned polished Si substrate by thermal decomposition of copper (II) oxide as temperature raised above $650{ }^{\circ} \mathrm{C}$. A mixture of high purity $\mathrm{ZnO}(99.999 \%)$ and activated carbon powders (mass ratio 1:2) was loaded at the end of a slender one-end sealed quartz tube (inner diameter $12 \mathrm{~mm}$, length $20 \mathrm{~cm}$ ). The copper island-coated silicon substrate was put into a small quartz tube as a collector (Fig. 1 (a)). Then the small quartz tube with a reactive source and silicon or quartz substrate was placed into a bigger quartz tube and pushed to the centre of the furnace. The reac- tants were heated at $1100{ }^{\circ} \mathrm{C}$. The temperature of the substrate region was lower than that of the reactants due to the temperature gradient, as shown in Fig. 1(b). After $2 \mathrm{~h}$ sintering, the small quartz tube was slowly cooled down to the room temperature in air and drawn out from the furnace. White and grayish-white colour products were formed on the surface of the silicon substrate.

The morphology of materials on the substrate was examined by a JEOL JSM-5910LV scanning electron microscope (SEM). X-ray diffractometry (XRD) patterns were obtained by a Siemens D5000 diffractometer using monochromatized $\mathrm{Cu} \mathrm{K} \alpha$ radiation $(\lambda=1.5418 \AA)$ under the accelerating voltage of $40 \mathrm{kV}$ and the current of $40 \mathrm{~mA}$ with a normal $\theta-2 \theta$ scan. Raman spectra of the sample were measured by using a Renishaw micro-Raman System 1000 spectrometer with excitation from an Ar+ laser operating at $514.5 \mathrm{~nm}$. Room-temperature PL was measured using a Hg lamp with an excitation wavelength of $365 \mathrm{~nm}$.

\section{Results and discussion}

Figure 2 shows various morphology of pure $\mathrm{ZnO}$ and $\mathrm{Cu}$ templated $\mathrm{ZnO}(\mathrm{ZnO} / \mathrm{CuO})$ structures on the Si substrate at different growth zones (or substrate temperatures). The pure micro-/nanostructure $\mathrm{ZnO}$ has a randomly columnar bonelike structure, a branched hemisphere, a comblike cantilever and a random wire at different (a)

Furnace

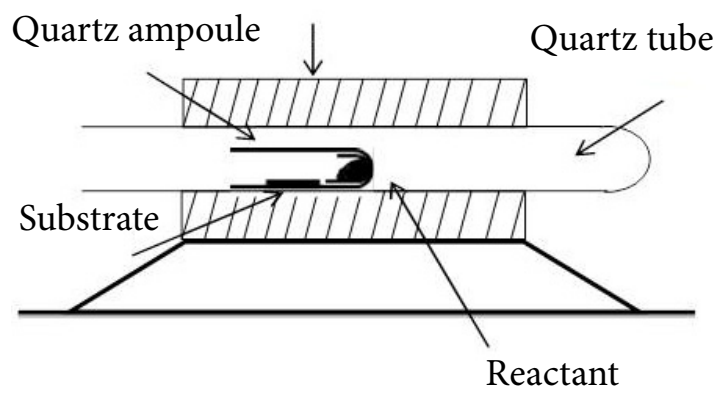

(b)

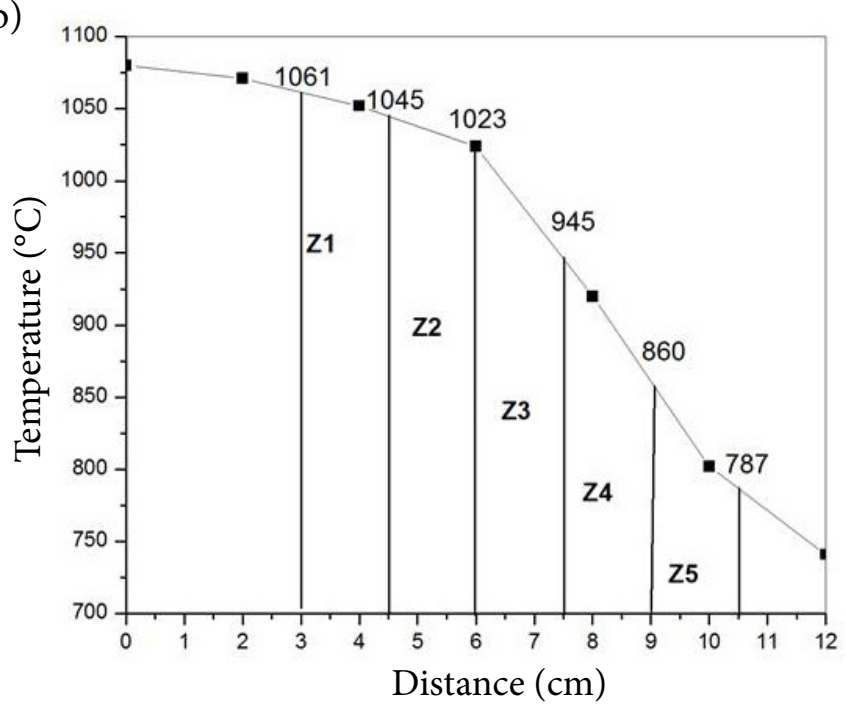

Fig. 1. Diagram of the furnace tube (a) and temperature profile of the furnace versus the distance between the substrate region and reactants (b). The temperature profile was measured using a ' $K$ ' type thermocouple. 


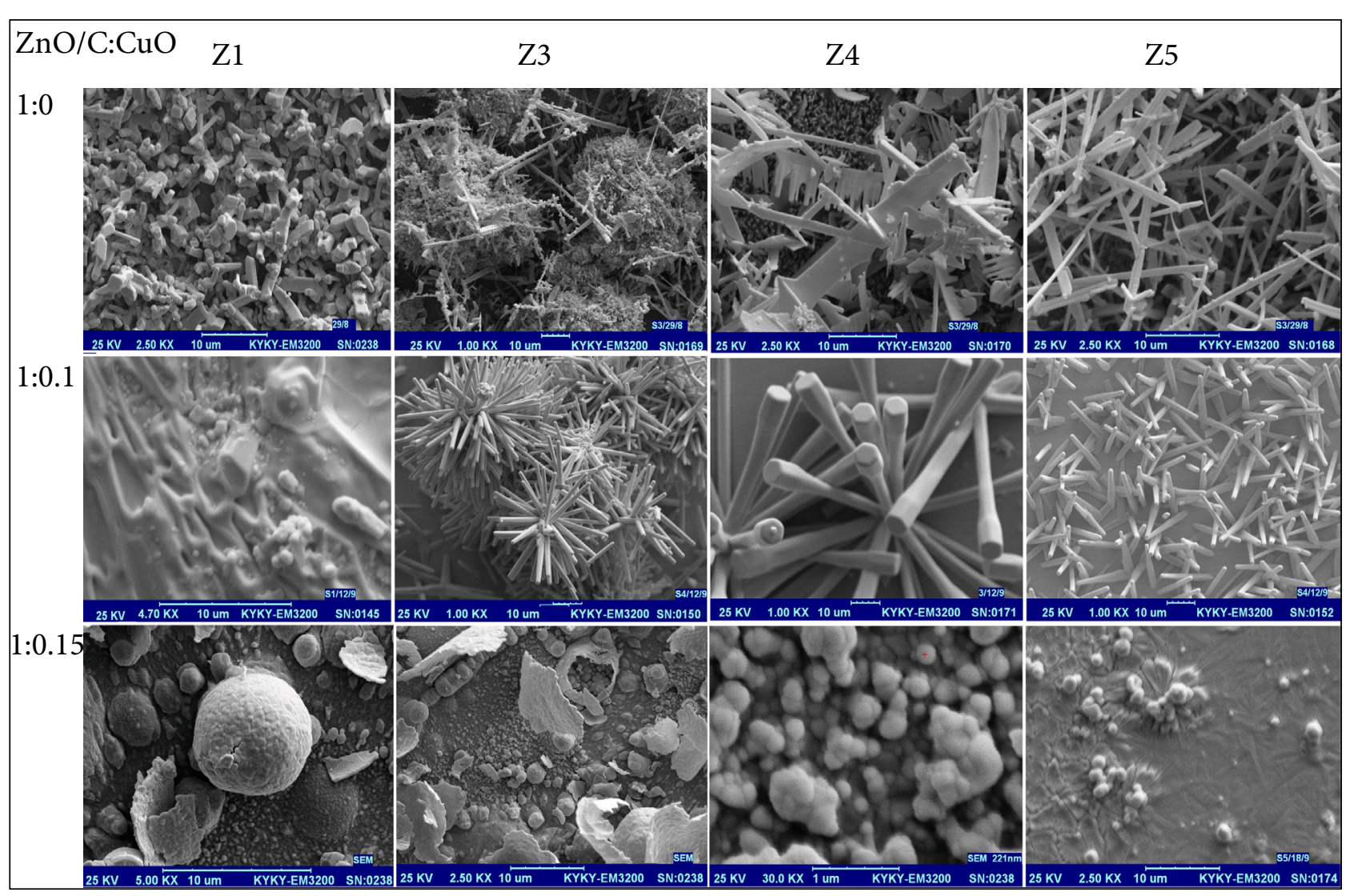

Fig. 2. Morphology of the pure $\mathrm{ZnO}$ and $\mathrm{CuO}_{x}$ template $\mathrm{ZnO}$ micro-/nanostructure on Si under different substrate temperature.

temperature zones Z1, Z3, Z4 and Z5, respectively. At the highest deposition temperature (Z1), the majority of the pure $\mathrm{ZnO}$ micro-/nanostructure consists of straight rods with a variable direction and diameter. Some of the rods merge together.

Hemisphere based wires (branched hemispheres) are formed with vapour condensation selectively on the concave tips between the branches where the chemical potential is lower than the convex and flat surface sites [20]. The comb-like cantilever of pure $\mathrm{ZnO}$ micro-/ nanostructures is the result of surface polarization induced growth due to the chemically active $(0001) \mathrm{Zn}[19,21]$. The comb structures have comb teeth growing along [0001], the top/bottom surfaces being $\pm(0 \overline{1} \overline{1} 0)$ and the side surfaces $\pm(2 \overline{1} \overline{1} 0)$. The comb structure is an asymmetric growth along $\mathrm{Zn} \mathrm{[0001]} \mathrm{[21].} \mathrm{The} \mathrm{positively}$ charged $\mathrm{Zn}^{+}$(0001) surface is chemically active and the negatively charged $\mathrm{O}^{-}(000 \overline{1})$ surface is relatively inert, resulting in growth of long fingers along [0001]. The Zn-terminated (0001) surface has tiny $\mathrm{Zn}$ clusters, which could lead to self-cata- lysed growth [21] without the presence of a foreign catalyst [21]. Anisotropic growth appears to be a common characteristic for the wurtzite family. A similar saw tooth growth has been observed for $\mathrm{ZnS}$ [22] and CdSe [23] and it is induced by Znand Cd-terminated (0001) surfaces, respectively. It was reported that $\mathrm{ZnO}$ wires might grow first along the [0001] direction, and then ultrafine nanoteeth might grow epitaxially along the $[11 \overline{2} 0]$ direction from the parent wires [21].

Finally, at the lowest deposition temperature ( $\mathrm{Z5}$ ), the $\mathrm{ZnO}$ micro-/nanostructure wires were randomly grown on the $\mathrm{Cu}$ nanoparticle deposited Si substrate. Therefore, the substrate distance from the source material and its temperature significantly affect the obtained morphology. This is most likely due to the variation in the rate of condensation (solidification) of $\mathrm{ZnO}$ species. The growth of the micro-/nanostructure is strongly dependent on the reactant $\left(\mathrm{Zn}\right.$ and $\left.\mathrm{O}_{2}\right)$, and therefore depends on the geometry of the experimental system, gas flow if any, as well as the type of the starting material. 
Figure 2 also depicts the morphology of $\mathrm{CuO}$ templated $\mathrm{ZnO}(\mathrm{ZnO} / \mathrm{CuO})$ micro-/nanostructures for the mass ratio of $\mathrm{ZnO}$ and $\mathrm{C}: \mathrm{Cu}$ (II)O as 1:0.1 and 1:0.15. The substrate surface was covered with a metallic $\mathrm{Cu}$ layer above the temperature of $650{ }^{\circ} \mathrm{C}$ (Cu wetting). Hence, a substantial coalescence between the $\mathrm{Cu}$ layer and $\mathrm{Zn}$ vapour induces a special distribution of adsorbed $\mathrm{Zn}$ and consequently the shape control of the $\mathrm{ZnO}$ micro-/ nanostructure during the growth process. Indeed, the $\mathrm{Cu}$ metal catalyst induces the formation of a multipod rod and a cage structure for the source nutrient of 1:0.1 and 1:0.15, respectively.

The morphology of $\mathrm{ZnO} / \mathrm{CuO}$ (mass ratio 1:0.1) micro-/nanostructures is javelin-shaped tetrapods (tetrapods having trumpet like arms). As can be seen, these javelins have a perfect hexagonal geometry. The average diameter of the javelins is about $7.80 \mu \mathrm{m}$ at the tip, and the average base diameter is $3.64 \mu \mathrm{m}$, with $40.42 \mu \mathrm{m}$ in length. The orientation of the javelin growth is preferentially along the direction of the $c$ axis ([0001]) because the $c$ axis is perpendicular to the hexagonal plane [24].

The coalescence appears to depend on the thickness of the $\mathrm{Cu}$ layer or equivalently on the distance between $\mathrm{Cu}$ particles. To minimize the total surface energy, small $\mathrm{Cu}$ particles incline to aggregate and form larger particles via the coalescence, leading to the growth of $\mathrm{ZnO}$ nuclei. The average distance between two neighbouring $\mathrm{ZnO}$ nuclei decreases quickly when the $\mathrm{Cu}$ layer is thicker. To understand this coalescence between $\mathrm{Zn}$ vapours in the presence of $\mathrm{Cu}$ particles, one has to consider the high-temperature alloying process between $\mathrm{Zn}$ vapour and $\mathrm{Cu}$ particles. At the growth temperature $\geq 787^{\circ} \mathrm{C}$ ( $\mathrm{Z} 5$ in Fig. 1(b)), the increase in the size of alloy droplets and its surface diffusion can account for spatial distribution and relaxation of $\mathrm{Zn}$ vapour on the $\mathrm{Cu}$ template as a catalyst.

After the supersaturation is reached, $\mathrm{Zn}$ probably condenses out of the $\mathrm{Cu}-\mathrm{Zn}$ alloy nuclei to form droplets. The size of the droplets is mainly determined by the global $\mathrm{Zn}$ vapour pressure in the furnace tube. To minimize the interface energy, the alloy nuclei tend to stay under the surface of these liquid-state $\mathrm{Zn}$ droplets. A very thin layer of $\mathrm{Cu}$ results in high density of $\mathrm{Zn}$ droplets.
These $\mathrm{Zn}$ droplets may make contact with each other and then merge into a continuous liquidstate network. Because the active $\mathrm{Zn}$ shows a large enthalpy of the formation of oxide [15], the interfacial interaction between the $\mathrm{Zn}$ and $\mathrm{Cu}$ template (layer) is strong. This layer is stable at the deposition temperature between $787-1061{ }^{\circ} \mathrm{C}$ and provides migration paths for the coalescence of $\mathrm{Zn}$ vapour in ambient air. In other words, the formation of a large scale metallic $\mathrm{Cu}$ layer occurs during the coalescence of $\mathrm{Cu}$ nuclei and facilitates the latter. As a result, larger $\mathrm{Cu}$ particles with a lower density are formed, which eventually leads to the growth of $\mathrm{ZnO}$ sites.

On the other hand, when the original $\mathrm{Cu}$ layer is thick, the $\mathrm{Zn}$ droplets are less likely to merge with each other to form a continuous layer owing to the fact that the barrier potential is larger. No continuous $\mathrm{Zn}$ layer is formed and $\mathrm{Zn}$ droplets remain separated throughout the whole process, leading to a rolled $\mathrm{ZnO}$ droplet (cage formation). Therefore, a liquid-state $\mathrm{Cu}$ layer determines the characteristics of the coalescent process and the size distribution of the grown $\mathrm{ZnO}$ shells or cages.

During the growth process in the presence of $\mathrm{Cu}$ catalysis, this transient liquid-metal layer gradually solidifies into separate $\mathrm{ZnO}$ geometries which terminate the migration and coalescence of $\mathrm{Zu}$ vapour. Naturally this $\mathrm{ZnO}$ layer emerges from the oxidized $\mathrm{Zn}$ rolled layer on top of the oxidized $\mathrm{Cu}$ template. There may be a close correlation between the $\mathrm{ZnO}$ coalescence and the formation of a continuous $\mathrm{Cu}$ buffer layer underneath the $\mathrm{ZnO}$ micro-/nanocages during the VLS growth. Such a buffer layer underneath the $\mathrm{ZnO}$ micro-/nanocages has not been reported previously, however, its role in the cage growth has not been elucidated so far. In contrast to the pure $\mathrm{ZnO}$ micro-/nanostructure, such buffer layer existed where the coalescent events were inhibited, and all $\mathrm{ZnO}$ micro-/ nanocages grew directly on the $\mathrm{Cu}$ coated $\mathrm{Si}$ substrate [15].

Because the formation of a template layer underneath the $\mathrm{ZnO}$ micro-/nanostructure is critically important to distribute spatially the $\mathrm{Zn}$ vapour, the factors determining its onset and characteristics to form separate $\mathrm{Zn}$ droplets are the surface coverage of $\mathrm{Cu}$ islands on the substrate. Regarding the first factor, the effect of oxidation 
competition between $\mathrm{Zn}$ droplets and $\mathrm{Cu}$, different $\mathrm{Cu}$ layer thicknesses and the effect of $\mathrm{Zn}$ pressure demonstrate that they are also critical parameters.

By changing the composition of the source material from 1:0.1 to 1:0.15, $\mathrm{ZnO}$ cages have been grown. In the temperature zone of $1020-1060{ }^{\circ} \mathrm{C}$, balls and polyhedra are observed; some of them are dispersed on the substrate and there appears to be no correlation among them, while some of them were formed in a higher temperature zone of typically $700-900{ }^{\circ} \mathrm{C}$.

Figure 3 shows the $\mathrm{X}$-ray diffraction pattern of a pure $\mathrm{ZnO}$ comb-like cantilever and a $\mathrm{CuO}$ templated $\mathrm{ZnO}$ javelin tetrapod and a polyhedral cage. The diffraction pattern of hexagonal wurtzite of the $\mathrm{ZnO}$ structure (JCPDS card No. 36-1451) with own related planes is observed for the pure $\mathrm{ZnO}$ comb-like cantilever. The diffraction peak intensity from the (101) plane has vanished from the sample deposited on the copper oxide template. The X-ray diffraction results indicate that the $\mathrm{ZnO}$ javelin and cage are grown with the $c$ axis orientation on the $\mathrm{CuO}_{x}$ template. The dominant appearance of the (100) and (002) peaks of $\mathrm{ZnO}$

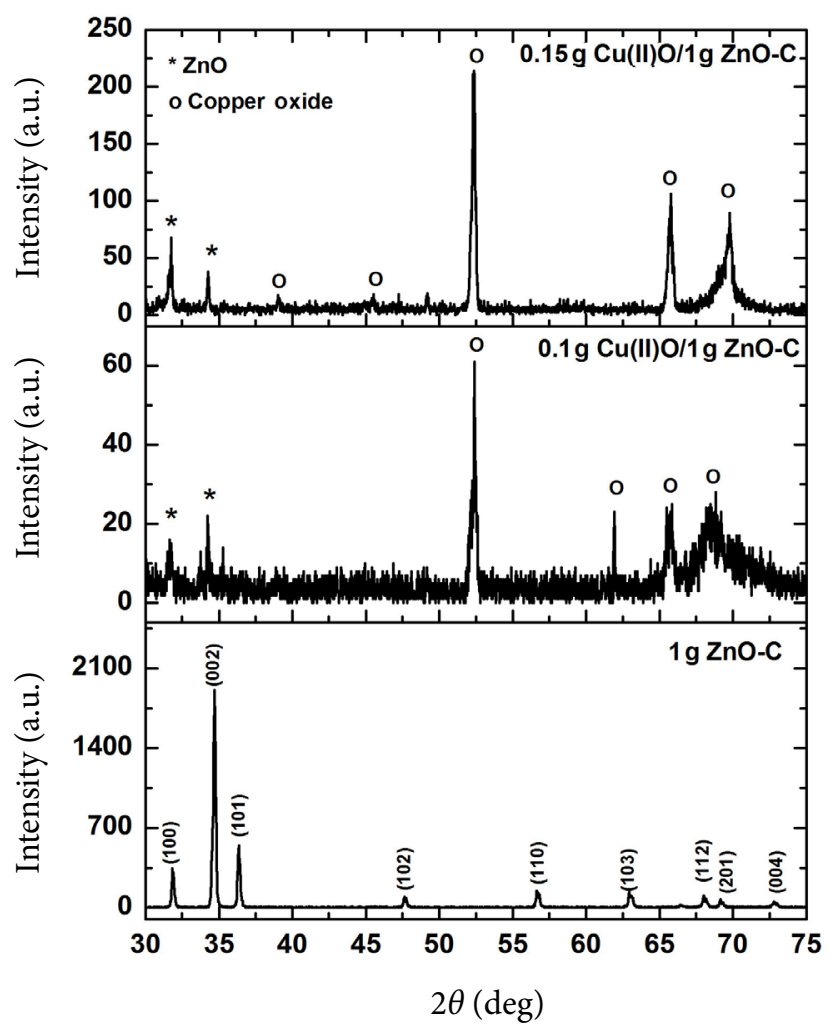

Fig. 3. XRD pattern of the $\mathrm{ZnO}-\mathrm{CuO}_{x}$ structure with (a) 0 , (b) $0.1 \mathrm{~g}$ and (c) $0.15 \mathrm{~g} \mathrm{Cu}(\mathrm{II}) \mathrm{O}$ in nutrient materials. shows its orientation relationship. The strong (002) peak of pure $\mathrm{ZnO}$ and $\mathrm{ZnO} / \mathrm{CuO}_{x}(1: 0.1)$ confirms the orientation of comb and javelin growth, respectively. Dominance of the (100) peak over the (002) peak for the source material of 1:0.15 confirms stopping of one-dimensional comb and rods growth along the (0001) direction and appearing of three-dimensional cage growth.

In a hexagonal structure, the lattice constant is calculated as [25]

$$
\frac{1}{d_{h k l}}=\frac{4}{3}\left[\frac{h^{2}+h k+k^{2}}{a^{2}}\right]+\frac{l^{2}}{c^{2}} .
$$

Using the (100) and (002) reflections and the Bragg relation $(2 d \sin \theta=\lambda), a$ and $c$ are calculated as

$$
a=\sqrt{\frac{4}{3}} \frac{\lambda}{2 \sin \theta_{100}}
$$

and

$$
c=\frac{\lambda}{\sin \theta_{002}},
$$

respectively. $\mathrm{Cu}$ enterance in the $\mathrm{ZnO}$ structure causes lattice expansion, because the $\mathrm{Cu}$ atomic radius $(1.73 \stackrel{\mathrm{A}}{\text { ) }}$ is larger than that of $\mathrm{Zn}$ (1.67 虽) [呴. The $\mathrm{ZnO}$ lattice constant $a=3.2478 \mathrm{~A}$, $c=5.2061 \AA$ [6]. As shown in the XRD pattern, the (002) peak is shifted towards the lower angle due to the $\mathrm{Cu}$ diffusion into the $\mathrm{ZnO}$ structure. This shift corresponds to an increase of the lattice constant. The calculated lattice constants are listed in Table 1. This dominant divalent state of $\mathrm{Cu}$ ions results from the strong $\mathrm{Cu}-\mathrm{O}$ bonding in copper oxide, which also lowers the $\mathrm{Cu}$ solubility in $\mathrm{ZnO}$. Hence, as seen from the XRD pattern, $\mathrm{Cu}$ segregates in copper oxide phases: monoclinic cupric $\mathrm{CuO}(a=4.6530 \mathrm{~A}, c=5.1080 \mathrm{~A})$ and cubic cuprous $\mathrm{Cu}_{2} \mathrm{O}(a=4.2520 \mathrm{~A})$ [26]. The growth of $\mathrm{CuO}_{x}$ underneath the $\mathrm{ZnO}$ structure causes the lattice constants of $\mathrm{ZnO}$ to expand. It might be due to the lattice misfit (mismatch) between adjacent phases and subsequent lattice distortion.

The $\mathrm{Zn}-\mathrm{O}$ bond length was calculated using [27]

$$
l=\sqrt{\frac{a^{2}}{3}+\left(\frac{1}{2}-u\right)^{2} c^{2}},
$$


where $u=\frac{a^{2}}{3 c^{2}}+0.25$ is the potential parameter of the hexagonal structure. The volume of a unit cell of the hexagonal system was calculated from Eq. 27]:

$$
V=0.866 a^{2} c
$$

The out-of-plane and in-plane stress $\left(\sigma_{\perp, \square}\right)$ in the $\mathrm{ZnO}$ plane can be determined by [28]

$$
\left[\begin{array}{c}
\sigma_{\text {out }} \\
\sigma_{\text {in }}
\end{array}\right]=-233 \times 10^{9}\left[\begin{array}{l}
\left(c_{\text {bulk }}-c\right) / c_{\text {bulk }} \\
\left(a_{\text {bulk }}-a\right) / a_{\text {bulk }}
\end{array}\right],
$$

where $a$ and $c$ are the lattice constants of the $\mathrm{ZnO}$ planes calculated from the X-ray diffraction data, $a_{\text {bulk }}$ and $c_{\text {bulk }}$ are the strain-free lattice parameters of $\mathrm{ZnO}$. The negative sign of stress indicates that the stress is compressive for the $\mathrm{ZnO}$ comb-like structure (Table 1). The stress is tensile when the $\mathrm{ZnO}$ micro-/nanostructure is grown on the copper oxide template (Table 1). This increase of tensile stress is due to the lattice distortion produced around a $\mathrm{Cu}$ atom inside the $\mathrm{Zn}-\mathrm{Cu}-\mathrm{O}$ lattice and $\mathrm{ZnO}-\mathrm{CuO}_{x}$ interface. The tensile stress persists and the lattices are distorted due to lower crystallinity. The calculated constant $c / a$ ratio (1.6) shows that there is no change in the hexagonal wurtzite structure [25] caused by growth on the $\mathrm{CuO}_{x}$ template. The observed shift in the XRD peak position, the d-value, cell parameters, bond length, volume and stress confirm the distortion of the $\mathrm{ZnO}$ structure.

Raman spectroscopy gives information on the vibrational properties of $\mathrm{ZnO}$ micro-/nanostructures. In the hexagonal structures with $\mathrm{C}_{6 v}^{4}$ symmetry like $\mathrm{ZnO}$, six sets of phonon normal modes at the $\Gamma$ point (centre of the Brillouin zone) are optically active modes [7]. The phonons for wurtzite $\mathrm{ZnO}$ belong to the following irreducible representation:

$$
\Gamma=A_{1}+E_{1}+2 B_{1}+2 E_{2} .
$$

The $A_{1}$ and $E_{1}$ modes are polar and split into transverse optical (TO) and longitudinal optical (LO) components. The $E_{2}$ modes are Raman active only. The $B_{1}$ modes are infrared and Raman inactive or silent modes. It is known that the $E_{2}$ (low) mode in $\mathrm{ZnO}$ is associated with the vibration of the heavy $\mathrm{Zn}$ sub-lattice and the $E_{2}$ (high) mode involves only oxygen atoms.

The $E_{2}$ (high) mode is characteristic of the wurtzite phase [29]. Figure 4 shows the Raman spectrum of $\mathrm{CuO}_{x}$ templated $\mathrm{ZnO}$ along with the spectrum of the pure $\mathrm{ZnO}$ for comparison. They are clearly indicative of a good wurtzite structure of the pure and $\mathrm{ZnO} / \mathrm{CuO}_{x}$ material. From Fig. 4 one observes the effect of the $\mathrm{CuO}_{x}$ template on the $E_{2}$ (high) mode of $\mathrm{ZnO}$ since its intensity decreases. The Raman signal indicates peaks at 446 and $444 \mathrm{~cm}^{-1}$ for the pure $\mathrm{ZnO}$ and

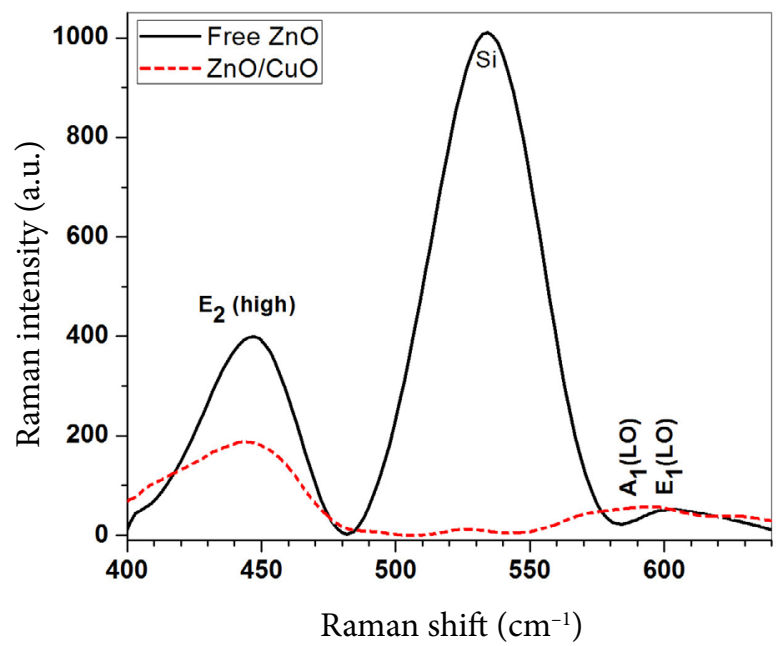

Fig. 4. Raman spectra of the pure $\mathrm{ZnO}$ and $\mathrm{ZnO} /$ $\mathrm{CuO}_{x}$ structure.

Table 1. The observed shift in the XRD peak position, cell parameters, bond length, cell volume and out- and in-plane stress in the $\mathrm{ZnO}$ comb, javelin and cage.

\begin{tabular}{c|c|c|c|c|c|c|c|c}
\hline $\mathrm{CuO}: Z n O$ & $2 \theta(\mathrm{deg})$ & $(h k l)$ & $a(\mathrm{~A})$ & $c(\mathrm{~A})$ & $\begin{array}{c}\text { Bond } \\
\text { length }(\mathrm{A})\end{array}$ & $\begin{array}{c}\text { Volume } \\
V\left(\mathrm{~A}^{3}\right)\end{array}$ & $\begin{array}{c}\text { Out-of-plane } \\
\text { stress } \sigma_{\perp} \\
(\mathrm{GPa})\end{array}$ & $\begin{array}{c}\text { In-plane } \\
\text { stress } \sigma_{\mu} \\
(\mathrm{GPa})\end{array}$ \\
\hline $0: 1$ & $\begin{array}{c}31.8235 \\
34.6941\end{array}$ & $\begin{array}{c}(100) \\
(002)\end{array}$ & 3.2470 & 5.1711 & 1.9724 & 47.2134 & -1.5664 & -0.0574 \\
\hline $0.1: 1$ & $\begin{array}{l}31.7412 \\
34.2470\end{array}$ & $\begin{array}{c}(100) \\
(002)\end{array}$ & 3.2551 & 5.2365 & 1.9836 & 48.0494 & 1.3606 & 0.5237 \\
\hline $0.15: 1$ & 31.6706 & $\begin{array}{c}(100) \\
(002)\end{array}$ & 3.2622 & 5.2365 & 1.9865 & 48.2592 & 1.3606 & 1.0331 \\
\hline
\end{tabular}


$\mathrm{ZnO} / \mathrm{CuO}_{x}$ material that shifted in the signal at $\sim 437 \mathrm{~cm}^{-1}$ for the $\mathrm{ZnO}$ micro-/nanostructure, which was also shifted in comparison to the Raman signal at $\sim 437 \mathrm{~cm}^{-1}$ for the $\mathrm{ZnO}$ micro-/ nanostructure grown by other techniques [30]. The Raman line of the $E_{2}$ (high) mode becomes broad and weaker, which means that the wurtzite crystalline structure of $\mathrm{ZnO}$ is weakened by high $\mathrm{CuO}_{x}$ templating and due to the formation of complex defects $\left[\mathrm{Cu}_{\mathrm{Zn}}-\mathrm{Zn}_{i}\right]^{x}$ in the $\mathrm{CuO}_{x}-\mathrm{ZnO}$ interface. The frequency shift was explained by alloy potential fluctuation (APF) using the spatial correlation model by Samanta et al. [31].

The intense peak near $439 \mathrm{~cm}^{-1}$ due to the $E_{2}$ (high) mode displays a clear asymmetry toward low frequencies. The asymmetric line shape has been successfully explained and analysed by Cusco et al. [32], in terms of resonant anharmonic interaction of the high- $E_{2}$ mode with a band of combined transverse and longitudinal acoustic modes, as the steep variation of the two-phonon density of states around the high- $E_{2}$ frequency leads to a distorted phonon line shape. Mixing of two different cations through doping in a solid solution could affect the local polarizability by charge distribution and result in at least one vibrational mode being strongly influenced [33].

In addition to the XRD pattern of pure $\mathrm{ZnO}$ and $\mathrm{ZnO} / \mathrm{CuO}_{x}$, high- $E_{2}$ frequency in Raman spectra confirms the formation of a $\mathrm{ZnO}$ hexagonal wurtzite structure. As shown in Fig. 4, there is no significant difference in the Raman spectra of the pure $\mathrm{ZnO}$ and $\mathrm{ZnO} / \mathrm{CuO}_{x}$ heterostructure. The lower Raman peak in the $\mathrm{ZnO} / \mathrm{CuO}_{x}$ heterostructure in comparison to that of the pure $\mathrm{ZnO}$ is related to a lower crystallinity that is in agreement with the XRD pattern.

Figure 5 depicts the variation of the bandgap energy of pure $\mathrm{ZnO}$ and $\mathrm{ZnO} / \mathrm{CuO}_{x}$ heterostructure absorption spectra. The $\mathrm{CuO}_{x}$ template and the distribution of $\mathrm{Cu}$ species during nucleation growth cause changes in the shape of $\mathrm{ZnO}$ from a teeth-like structure to a javelin and, finally, a cage structure. On the other hand, the bandedge of $\mathrm{ZnO} / \mathrm{CuO}_{x}$ is redshifted in comparison to the pure micro-/nanostructure. It is worthwhile to notice that the bandgap shrinkage of the $\mathrm{ZnO} /$ $\mathrm{CuO}_{x}$ heterostructure cannot be substantially dependent on the morphology of the $\mathrm{ZnO}$ micro-/ nanostructure. But the $\mathrm{CuO}_{x}$ template signifi-

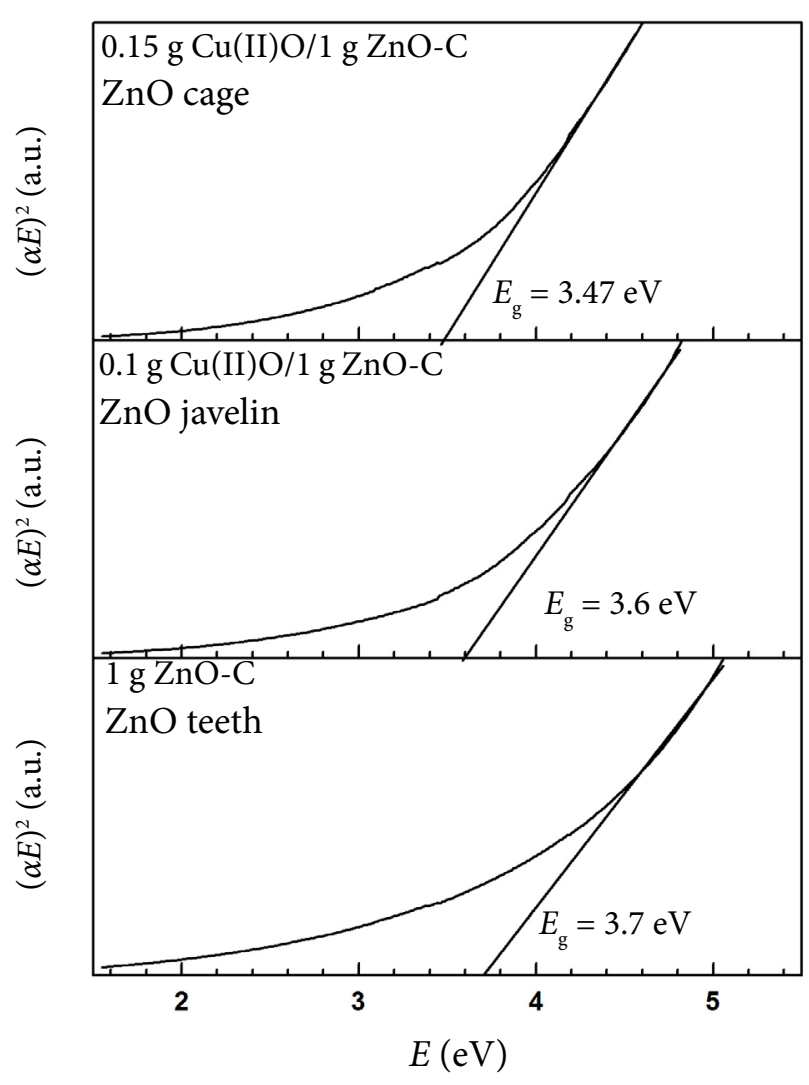

Fig. 5. Absorption spectrum of (a) the pure $\mathrm{ZnO}$ teeth, (b) the $\mathrm{ZnO}$ javelin on the $\mathrm{CuO}_{x}$ template with $0.1 \mathrm{~g}$ and (c) the $\mathrm{ZnO}$ cage on the $\mathrm{CuO}_{x}$ template with $0.15 \mathrm{~g} \mathrm{Cu}(\mathrm{II}) \mathrm{O}$ in nutrient materials.

cantly causes the bandgap to reduce. Depending on the processing parameters during deposition, copper oxide can exist in two crystalline phases with p-type conductivity: a cuprous oxide $\left(\mathrm{Cu}_{2} \mathrm{O}\right)$ cubic structure with a direct band gap range of 2.1-2.6 eV and a cupric oxide $(\mathrm{CuO})$ monoclinic structure with a direct band gap of 1.3-2.1 eV. These oxides exhibit a high absorption coefficient in the visible region and can be grown by a variety of techniques [ [4, 12]. The out-plane and in-plane stress (Table 1) can provide another mechanism to bandgap narrowing.

\subsubsection{Photoluminescence study}

Figure 6(a) shows the PL spectrum of $\mathrm{ZnO}$ branched hemisphere and comb-like cantilever structures. The branched hemisphere has only a green emission around $545 \mathrm{~nm}$, but the comblike cantilever has two emitting bands including a UV emission at around $393 \mathrm{~nm}$ and as well as 
a green band around $521 \mathrm{~nm}$. The comb-like cantilever structure exhibits near-band-edge emission (NBE), in comparison to the branched hemisphere structure, due to a good crystalline quality in the comb-like cantilever [34]. The difference between the green emission from the comb-like cantilever and the branched hemisphere structures is related to defect concentration.

It has been suggested that the green band emission corresponds to the singly ionized oxygen vacancy in $\mathrm{ZnO}$ and results from the recombination of a photogenerated hole with the singly ionized charge state of this defect. The stronger the intensity of the green luminescence is, the more singly ionized oxygen vacancies are [21, 35]. For the green emission, though a number of hypotheses have been proposed, some assignments are highly controversial. Typical works reported that
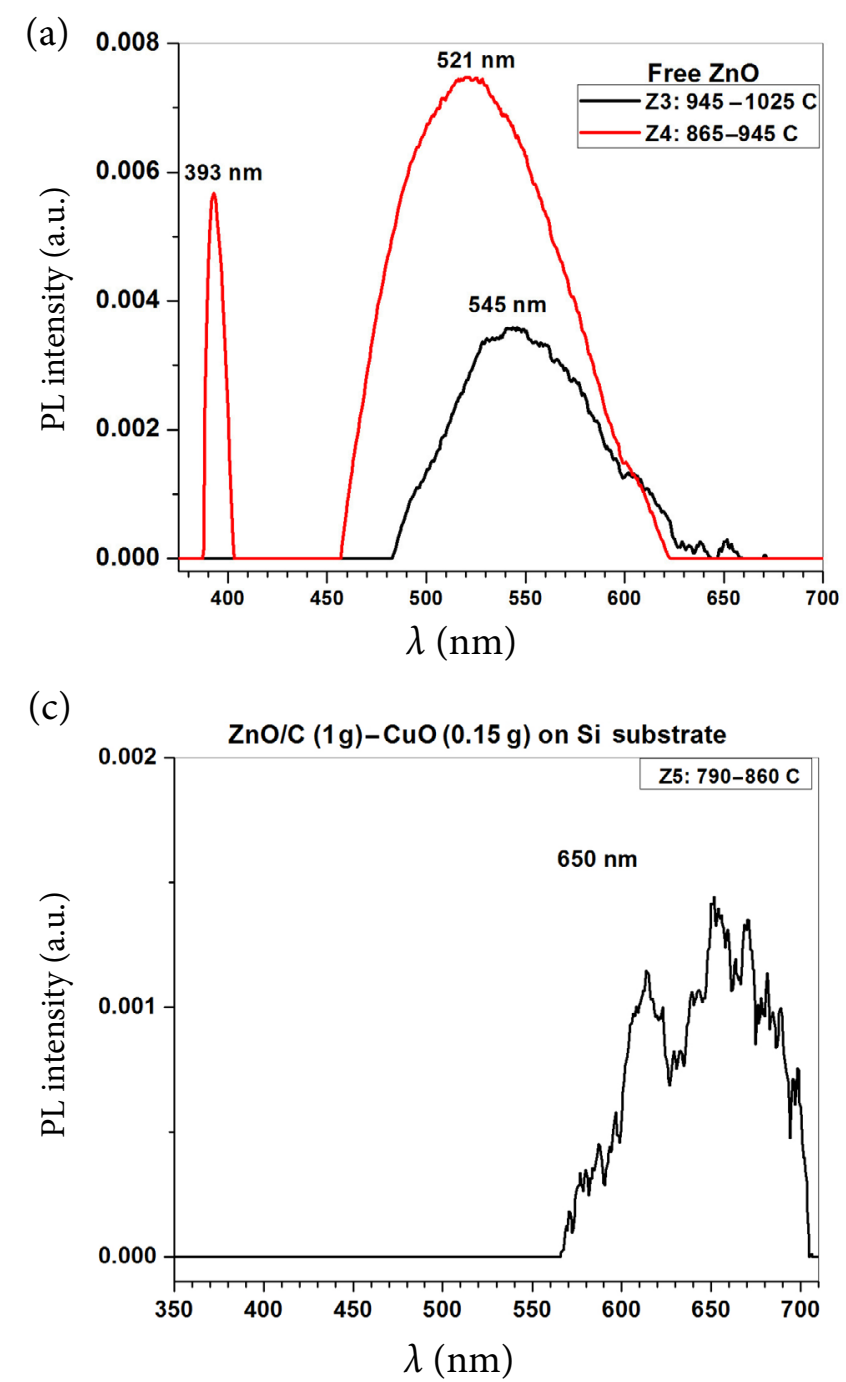

the transitions might occur between singly ionized oxygen vacancies and photoexcited holes, or electrons close to the conductive band and deeply trapped holes at $\mathrm{V}_{\mathrm{O}}^{2+}$ antisite oxygen, zinc interstitials, zinc vacancies, etc. [35, 36]. The yelloworange band emission is attributed to the oxygen interstitial defects located in the bulk [35, 36].

Figure 6(b) shows the PL spectrum of the $\mathrm{ZnO}$ javelin-like tetrapod and curved tip rod structures. The $\mathrm{ZnO}$ javelin-like tetrapod structure has only a green emission around $523 \mathrm{~nm}$. The $\mathrm{ZnO}$ curved tip rod structures have three emitting bands, including a strong ultraviolet emission-excitonic recombination at around $388 \mathrm{~nm}$, a blue band $(486 \mathrm{~nm})$ as well as a green band $(523 \mathrm{~nm})$ observed. The UV emission must be contributing to the near band edge emission of the wide band-gap $\mathrm{ZnO}$. The observation of the blue band emission

(b)

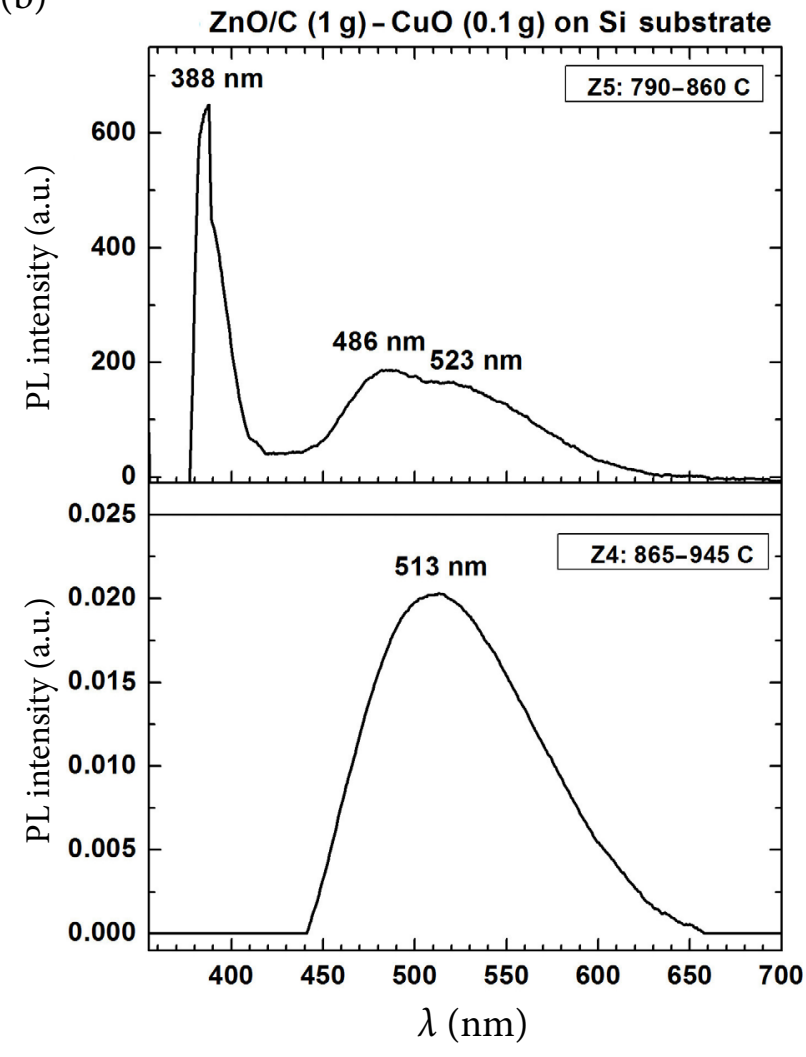

Fig. 6. Absorption spectrum of (a) the pure $\mathrm{ZnO}$ teeth and the $\mathrm{CuO}_{x}$ templated $\mathrm{ZnO}$ with (b) $0.1 \mathrm{~g}$ and (c) $0.15 \mathrm{~g} \mathrm{Cu}(\mathrm{II}) \mathrm{O}$ in nutrient materials. 
$(486 \mathrm{~nm})$ of the $\mathrm{ZnO}$ film has also been reported [21], using cathodoluminescence. Figure 6(c) also depicts a weak red emission of the $\mathrm{ZnO}$ polyhedral cage around $650 \mathrm{~nm}$, which may be attributed to the contribution of $\mathrm{Cu}$ template oxidation.

\section{Conclusions}

$\mathrm{ZnO} / \mathrm{CuO}_{x}$ hetero-micro-/nanostructures were synthesized by the carbothermal reductionchemical vapour transport method. This work is focused on tuning the shape and geometry of the $\mathrm{ZnO}$ micro-/nanostructure to the substrate temperature, $\mathrm{Cu}$ catalyst layer. The thermally oxidized $\mathrm{Cu}$ template underneath the $\mathrm{ZnO}$ structure $\left(\mathrm{ZnO} / \mathrm{CuO}_{x}\right.$ heterostructure) affects its structure and chemical identity, optical and photoluminescence properties. A stable hemisphere based wire, a comb-like cantilever, a javelin-like tetrapod, a spherical and polyhedral cage of a hexagonal wurtzite structure of the $\mathrm{ZnO}$ micro-/nanostructure are formed depending on the deposition condition. The absorption edge of the $\mathrm{ZnO} / \mathrm{CuO}_{x}$ heterostructure is redshifted in comparison to the pure $\mathrm{ZnO}$ structure. It is possible to tune the PL spectra from green to UV and, finally, red emission by growth temperature and precursor composition.

\section{Acknowledgements}

The authors would like to acknowledge the financial support of the Iranian Nanotechnology Initiative. Ali Rahmati (the corresponding author) is grateful to Dr. Masoud Karimipour and Dr. Mehdi Molaei for fruitful discussions.

\section{References}

[1] Z. Zhang, S.J. Wang, T. Yu, and T. Wu, Controlling the growth mechanism of $\mathrm{ZnO}$ nanowires by selecting catalysts, J. Phys. Chem. C 111, 1750017505 (2007).

[2] M. Laurenti, S. Stassi, M. Lorenzoni, M. Fontana, G. Canavese, V. Cauda, and C.F. Pirri, Evaluation of the piezoelectric properties and voltage generation of flexible zinc oxide thin films, Nanotechnology 26, 215704 (2015).
[3] M. Laurenti, G. Canavese, A. Sacco, M. Fontana, K. Bejtka, M. Castellino, C.F. Pirri, and V. Cauda, Nanobranched $\mathrm{ZnO}$ structure: p-type doping induces piezoelectric voltage generation and ferroelectric-photovoltaic effect, Adv. Mater. 27, 4218-4223 (2015).

[4] A. Rahmati and S. Zakeri Afshar, Heteroepitaxial $\mathrm{ZnO} / \mathrm{CuO}$ thin film and nanorods array: photoconductivity and field emission effect, J. Mater. Sci. Mater Electron. 28, 13032 (2017), https://doi. org/10.1007/s10854-017-7135-8

[5] A. Rahmati and M. Yousefi, Well oriented $\mathrm{ZnO}$ nanorods arrray: negative resistance and optical switching, Z. Anorg. Allg. Chem. 643, 870-876 (2017).

[6] Ü. Özgür, Ya. I. Alivov, C. Liu, A. Teke, M.A. Reshchikov, S. Doğan, V. Avrutin, S.-J. Cho, and H. Morkoç, A comprehensive review of $\mathrm{ZnO}$ materials and devices, J. Appl. Phys. 98, 041301 (2005).

[7] H. Morkoç and Ü. Özgür, in: Zinc Oxide, Fundamentals, Materials and Device Technology (Wiley VCH, 2009).

[8] U. Manzoor and D.K. Kim, Size control of $\mathrm{ZnO}$ nanostructures formed in different temperature zones by varying Ar flow rate with tunable optical properties, Physica E 41, 500-505 (2009).

[9] W.I. Park, D.H. Kim, S.W. Jung, and G.C. Yi, Metalorganic vapour-phase epitaxial growth of vertically well-aligned $\mathrm{ZnO}$ nanorods, Appl. Phys. Lett. 80, 4232 (2002).

[10]A.B. Hartanto, X. Ning, Y. Nakata, and T. Okada, Growth mechanism of $\mathrm{ZnO}$ nanorods from nanoparticles formed in a laser ablation plume, Appl. Phys. A 78, 299 (2004).

[11]L. Vayssieres, K. Keis, S.E. Lindquist, and A.J. Hagfeldt, Purpose-built anisotropic metal oxide material: 3D highly oriented microrod array of ZnO, Phys. Chem. B 105, 3350 (2001).

[12]C.R. Gobbiner, A.V. Muhammed Ali, and D. Kekuda, $\mathrm{CuO} / \mathrm{ZnO}$ planar bilayer heterojunction grown by reactive dc magnetron sputtering, J. Mater. Sci. Mater. Electron. 26, 9801-9807 (2015).

[13]Y.W. Heo, V. Varadarajan, M. Kaufman, K. Kim, D.P. Norton, F. Ren, and P.H. Fleming, Sitespecific growth of $\mathrm{ZnO}$ nanorods using catalysis- 
driven molecular-beam epitaxy, Appl. Phys. Lett. 81(16), 3046-3048 (2002).

[14]M.H. Huang, Y. Wu, H. Feick, N. Tran, E. Weber, and P. Yang, Catalytic growth of zinc oxide nanowires by vapour transport, Adv. Mater. 13(2), 113-116 (2001).

[15]D.L. Guo, X. Huang, G.Z. Xing, Z. Zhang, G.P. Li, M. He, H. Zhang, H.Y. Chen, and T. Wu, Metallayer-assisted coalescence of $\mathrm{Au}$ nanoparticles and its effect on diameter control in vapour-liquid-solid growth of oxide nanowires, Phys. Rev. B 83, 045403 (2011).

[16]G.W. She, X. Huang, L.L. Jin, X.P. Qi, L. Mu, and W.S. Shi, Electrochemical sensors: $\mathrm{SnO}_{2}$ nanoparticle-coated $\mathrm{ZnO}$ nanotube arrays for high-performance electrochemical sensors, Small 10(22), 4685-4692 (2014).

[17]F.M. Li, G.W. Hsieh, S. Dalal, M.C. Newton, J.E. Stott, P. Hiralal, A. Nathan, P.A. Warburton, H.E. Unalan, P. Beecher, A.J. Flewitt, I. Robinson, G. Amaratunga, and W.I. Milne, Zinc oxide nanostructures and high electron mobility nanocomposite thin film transistors, IEEE Trans. Electron Dev. 55(11), 3001 (2008).

[18]B.D. Yao, Y.F. Chan, and N. Wang, Formation of $\mathrm{ZnO}$ nanostructures by a simple way of thermal evaporation, Appl. Phys. Lett. 81, 757 (2002).

[19]Z.L. Wang, X.Y. Kong, and J.M. Zuo, Induced growth of asymmetric nanocantilever arrays on polar surfaces, Phys. Rev. Lett. 91, 185501 (2003).

[20]G. Modi, Zinc oxide tetrapod: a morphology with multifunctional applications, Adv. Nat. Sci. Nanosci. Nanotechnol. 6, 033002 (2015).

[21]Z.L. Wang, Zinc oxide nanostructures: growth, properties and applications, J. Phys. Condens. Matter 16, R829-858 (2004).

[22]D. Moore, C. Ronning, C. Ma, and Z.L. Wang, Wurtzite $\mathrm{ZnS}$ nanosaws produced by polar surfaces, Chem. Phys. Lett. 385, 8 (2004).

[23]C. Ma, Y. Ding, D. Moore, X.D. Wang, and Z.L. Wang, Single-crystal CdSe nanosaws, J. Am. Chem. Soc. 126, 708 (2004).

[24]R. Yousefi, F. Jamali-Sheini, A. Khorsand Zak, and M.R. Mahmoudian, Effect of indium concentration on morphology and optical properties of In-doped $\mathrm{ZnO}$ nanostructures, Ceram. Int. 38, 6295-6301 (2012).

[25]B.D. Cullity, Elements of X-ray Diffractions (Addison-Wesley, Reading, MA, 1978).

[26]S.W. Lee, Y.S. Lee, J.Y. Heo, S.C. Siah, D. Chua, R.E. Brandt, S.B. Kim, J.P. Mailoa, T. Buonassisi, and R.G. Gordon, Improved $\mathrm{Cu}_{2} \mathrm{O}$-based solar cells using atomic layer deposition to control the $\mathrm{Cu}$ oxidation state at the p-n junction, Adv. Energy Mater. 4(11), 1301916 (2014).

[27]G. Srinivasan, R.T.R. Kumar, and J. Kumar, Li doped and undoped $\mathrm{ZnO}$ nanocrystalline thin films: a comparative study of structural and optical properties, J. Solgel Sci. Technol. 43, 171-177 (2007).

[28]O. Lupan, T. Pauporte, L. Chow, B. Viana, F. Pelle, L.K. Ono, B.R. Cuenya, and H. Heinrich, Effects of annealing on properties of $\mathrm{ZnO}$ thin films prepared by electrochemical deposition in chloride medium, Appl. Surf. Sci. 256, 1895-1907 (2010).

[29] O. Lupan, L. Chow, L.K. Ono, B. Roldan Cuenya, G. Chai, H. Khallaf, S. Park, and A. Schulte, Synthesis and characterization of Ag- or Sbdoped $\mathrm{ZnO}$ nanorods by a facile hydrothermal route, J. Phys. Chem. C 114, 12401-12408 (2010).

[30]P.K. Sharma, R.K. Dutta, and A.C. Pandey, Doping dependent room-temperature ferromagnetism and structural properties of dilute magnetic semiconductor $\mathrm{ZnO}: \mathrm{Cu}^{2+}$ nanorods, J. Magn. Magn. Mater. 321, 4001-4005 (2009).

[31]K. Samanta, P. Bhattacharya, R.S. Katiyar, W. Iwamoto, P.G. Pagliuso, and C. Rettori, Raman scattering studies in dilute magnetic semiconductor $\mathrm{Zn}_{1-x} \mathrm{Co}_{x} \mathrm{O}$, Phys. Rev. B 73, 245213 (2006).

[32]R. Cusco, E. Alarcon-Llado, J. Ibanez, L. Artus, J. Jimenez, B. Wang, and M. Callahan, Temperature dependence of Raman scattering in $\mathrm{ZnO}$, Phys. Rev. B 75, 165202 (2007).

[33]X.F. Wang, J.B. Xu, X.J. Yu, K. Xue, and X. Zhao, Structural evidence of secondary phase segregation from the Raman vibrational modes in $\mathrm{Zn}_{1-x} \mathrm{Co}_{x} \mathrm{O} \quad(0<x<0.6)$, Appl. Phys. Lett. 91, 031908 (2007).

[34]M. Karaliunas, T. Serevicius, E. Kuokstis, S. Jursenas, S.Y. Ting, J.J. Huang, and C.C. Yang, 
Optical characterization of MBE-grown $\mathrm{ZnO}$ epilayers, Adv. Mat. Res. 222, 86-89 (2011).

[35]D.D. Wang, G.Z. Xing, J.H. Yang, L.L. Yang, M. Gao, J. Cao, Y.J. Zhang, and B. Yao, Dependence of energy transfer and photoluminescence on tailored defects in Eu-doped $\mathrm{ZnO}$ nanosheets-based microflowers, J. Alloy. Comp. 504, 22-26 (2010).

[36]G.Z. Xing, G.C. Xing, M.J. Li, E.J. Sie, D. Wang, A. Sulistio, Q.L. Ye, C. Hon, A. Huan, T. Wu, and T.C. Sum, Charge transfer dynamics in $\mathrm{Cu}$-doped ZnO nanowires, Appl. Phys. Lett. 98, 102105 (2011).

\title{
IVAIRIALYTIS $\mathrm{CuO}_{x} / \mathrm{ZnO}$ MIKRO- ARBA NANODARINYS: KARBOTERMINE் REDUKCIJA SU GARŲ FAZĖS PERNAŠA
}

\author{
A. Rahmati ${ }^{\text {a, b }}$, F. Rahimi Bayaz ${ }^{\text {a, b }}$, A. Lotfiani ${ }^{c}$, M. Kouhestani ${ }^{\text {d }}$ \\ ${ }^{a}$ Rafsandžano Vali-e-Asr universiteto Mokslo fakulteto Fizikos katedra, Rafsandžanas, Iranas \\ ${ }^{\mathrm{b}}$ Rafsandžano Vali-e-Asr universiteto Mokslo fakulteto Nanostruktūrų laboratorija, Rafsandžanas, Iranas \\ ‘ ̌̌ahid Behešti universitetas, Evinas, Teheranas, Iranas \\ ${ }^{d}$ Pajam Nur universitetas, Teheranas, Iranas
}

